\title{
Scientific Thinking Skills in Science Among Third Intermediate Grade Female Students in Riyadh in Saudi Arabia
}

\author{
Noura Bint Saeed Ibn Ali Al-Qahtani, Ali Ibn Ahmad Ibn Saleh Al-Rashid \\ Department of Curriculum \& Instruction, Faculty of Education, King Saud University, Riadh, Kingdom of Saudi Arabia
}

Email address:

N.moonlight1@hotmail.com (N. B. S. I. A. Al-Qahtani),nq.3322@gmail.com (A. I. A. I. S. Al-Rashid)

\section{To cite this article:}

Noura Bint Saeed Ibn Ali Al-Qahtani, Ali Ibn Ahmad Ibn Saleh Al-Rashid. Scientific Thinking Skills in Science Among Third Intermediate Grade Female Students in Riyadh in Saudi Arabia. International Journal of Science, Technology and Society.

Vol. 9, No. 4, 2021, pp. 173-181. doi: 10.11648/j.ijsts.20210904.14

Received: May 25, 2021; Accepted: July 13, 2021; Published: August 7, 2021

\begin{abstract}
This research aimed to detect the level of scientific thinking skills in science among female students of thirdintermediate grade in the schools of Annahdah Office, Eastern Riyadh city. The researcher used the descriptive survey methodology which included two main tools: Scientific Thinking Skills Scale which was applied on a sample of (673) female students and divided into three themes: the skill of doubt in information before acceptance, the skill of logical reasoning of information, the skill of reliance on empirical evidence to judge information. And a questionnaire that included science female teachers' perspectives regarding the level of female students practice of scientific thinking skills, and was applied on a sample of (80) science female teachers. Results showed that the level of practicing scientific thinking skills in science among female students of third-intermediate grade was low based on the scale results. Where the level of practicing skills of doubt of information before acceptance was (71\%), The level of practicing skills of logical reasoning of information was (29\%). The level of practicing skills of reliance on empirical evidence to judge information was (32\%). Results of the questionnaire showed that the level of practicing scientific thinking skills among 9th female students was also high from the science teachers' perspectives. Where the level of the teachers' perspectives of the student skills of doubt of information before acceptance was (63\%), the skills of logical reasoning of information was $(85 \%)$ and the skills of reliance on empirical evidence to judge information was (66\%). The research concluded a number of recommendations, the most important are: constructing enrichment materials and programs that aim to the development of scientific thinking skills among female students.
\end{abstract}

Keywords: Scientific Thinking Skills, Science, Female Students, Third-Intermediate Grade, Riyadh

\section{Introduction}

The knowledge inflation and the rapid development achieved by countries in the technology field is nothing but a product of a human intellectual activity, and this is what prompts all educational institutions in all those countries to direct this activity towards working to provide the learner with the skill of thinking. In other words, he learns how to think, and to be able to discover scientific facts and understand natural phenomena, and how and why it occur. This makes the learner aware of the information and knowledge that he acquires; which gives him an opportunity to creativity, innovation and finding everything that is authentic.
Thinking is one of the intellectual mental processes with higher knowledge, which lies behind the development of human life, his control over various living creatures, and the extent of findig effective solutions that a human can overcome by counter problems and difficulties he faces. Most of the achievements that humanity has achieved are based on thinking [7]. Therefore, thinking is the basis for solving various life problems and scientific discoveries in our current era. The development of thinking and its various skills has become a necessity in our daily and practical lives and in countering challenges of the twenty-first century, which requires the preparation and processing of various educational situations that help support the thinking process of the learner. Therefore, education must be in order to 
develop different thinking skills, so that it becomes a general behavior practiced by the learner inside and outside the school [19].

EL-Sabagh [8] confirms that the task of preparing the future generation has become at the heart of the objectives of scientific education by working to provide individuals with skills that enable them to deal with the variables and problems resulting from the development of science and technology, and that what many students use outside school and what then much more than they will learn in it. Therefore, the biggest challenge in modern teaching methods is giving the learner a greater role in the learning and teaching processes to gain different experiences and develop his thinking skills, taking into account the interest in the integrated growth of the learner's personality, needs and desires.

Therefore, improving science education and learning to develop scientific thinking skills requires the learner to achieve experiences and activities on his own without the need for memorization, discover a directed discovery, and provide explanations for phenomena and solutions to problems and compare it with explanations related to science and technology [2].

Based on the education policy in the Kingdom of Saudi Arabia, which paid special attention to scientific thinking through some of the objectives mentioned in phrases (41) and (99) of the master plan for education policy, which emphasized the importance of encouraging the spirit of scientific research and thinking, developing the ability to watch and contemplation among learners, and deepening the spirit of research, experimentation and systematic tracking [21]. It was necessary to focus on developing the scientific thinking skills because of its importance in the learners life, building a society conscious of what is going on around it, and it is a type of complex thinking needs to use higher mental processes, which can only be obtained by having the ability to sort and doubt information before accepting it and relying on trusted information proven by logic, practical, and empirical reality, so that the results and decisions based on it are correct.

\subsection{Problem of the Research}

Recently, the demands that urge attention strongly to scientific thinking have increased, because of its great importance according to the rapid life developments, and making it a major task for the teacher and designers of science curricula. The importance of scientific thinking is highlighted in the current period of time, which is characterized by modern developments and the dominance of major countries over the flow of information, the dissemination of Western culture with its values that contradict Islamic values, the adoption of most Islamic countries by its path and approach, and technological and technical developments in the field of media and information, represented in direct broadcasting, satellite channels and social networks, which have effectively contributed to spreading ideas, being influenced by it and changing the values of individuals [9].

In the same context, Zimmerman [20] believes that the development of scientific thinking skills is one of the goals of teaching science curricula, as scientific thinking skills help in the search for logical methods in the exploration and interpretation of phenomena or problems facing the learner during his study or his daily and future life.

Some studies have been conducted that focused on scientific thinking, such as Silk [18] study, which indicated that students still lack many scientific skills, and they are less able to solve their problems by scientific methods based on experimentation and reasoning. As well as Remigio [15] study indicated that students still lack the ability to analyze, evaluate and conclude, which is one of the most important skills of scientific thinking, and these studies agreed that students lack scientific thinking skills..

Moreover, since the development of scientific thinking skills is an integral part of the curricula at all school levels; the Kingdom of Saudi Arabia has sought to change its curricula, to be advanced curricula aimed at developing all kinds of thinking, including scientific thinking. Therefore, the need to conduct this research came to determine the practice level of scientific thinking skills in science for thirdgrade intermediate students, by measuring the level of students' practice of scientific thinking skills.

\subsection{Objectives of the Research}

The research aimed to detect the practice level of scientific thinking skills in science by third intermediate grade students. The following sub-objectives stems from the main objective:

1) Identifying the practice level of the third intermediate grade students of the skill of doubt in information before acceptance in science subject.

2) Identifying the practice level of the third intermediate grade students of the skill of logical reasoning of information in science subject.

3) Recognizing the practice level of the third intermediate grade students of the skill of reliance on empirical evidence to judge information in science subject based on their abilities, observations, and experiences.

\subsection{Importance of the Research}

The importance of the research lies in the following:

\subsubsection{Scientific Significance (Theoretical)}

1) The importance of developing scientific thinking skills in daily life due to cognitive acceleration, and then its reflection on their ability to apply these skills in solving life problems.

2) Adding a valid and reliable measure of scientific thinking in the Saudi environment, may help educational researchers when conducting other relevant research.

\subsubsection{Practical (Applied) Importance}

1) Knowing the practice level of scientific thinking skills by third intermediate grade students, and making recommendations in order to achieve quality and 
excellence in the educational process.

2) Directing the attention of education officials and putting them in reality of obstacles and solutions, by identifying the aspects and skills that should receive attention, especially with regard to the issue of problems encountering the implementation of curricula.

\subsection{Questions of the Research}

Questions of the research were determined in the following main question:

What is the practice level of the scientific thinking skills among the third intermediate grade students in the sciences subject?

The following sub-questions emerge from the main question:

I. What is the practice level of the skill of doubt in information before acceptance among the third intermediate grade female students in the sciences?

II. What is the practice level of the skill of logical reasoning of information among the third intermediate grade female students in the sciences?

III. What is the practice level of the skill of reliance on empirical evidence to judge information among the third intermediate grade female students in the sciences subject?

\subsection{Terms of the Research}

Scientific thinking: It is "A mental process requires the learner to have previous knowledge and experience in order to be able to take organized steps and specific procedures to remove confusion from achieving his aim" [3]. The researcher defines it procedurally: it is an organized thinking pattern carried out by the female student in logical and intentional scientific steps, based on convincing mental evidence, in order to discover an unknown truth or prove an existing fact, and it is measured by a scale prepared by the researcher.

\subsection{Limits of the Research}

Limits of the research are confined to the following:

\subsubsection{Objective Limits}

The current research is limited to studying the practice level of scientific thinking among third intermediate grade female students in three themes: the skill of doubt in information before acceptance, the skill of logical reasoning of information, and the skill of reliance on empirical evidence to judge information.

\subsubsection{Human Limits}

A sample of science students and teachers in the third intermediate grade.

\subsubsection{Spatial Boundaries}

Schools affiliated to the Education Office in Al-Nahda, East of Riyadh.

\subsubsection{Time Limits}

The second semester of the academic year 1436/1437 AH.

\section{Theoretical Framework}

\subsection{The Scientific Thinking}

The interest in scientific thinking focused clearly, because of its close relationship with scientific and technical development. This reflected in scientific education, which focused on developing the skills of inquiry and scientific research among learners, and its employment in various areas of life. Such interest emerged in the United States of America. Some projects have been developed for science education such as Biological Science Curriculum Study (BSCS) \& Physical Science Study Committee (PSSC), and then this interest extended to the rest of the world. These projects were based on a number of pillars, including: that scientific thinking includes a number of abilities and logical processes, and such abilities can be developed in learners, by providing all appropriate opportunities for them to practice it [4].

Al-Hadabi [3] confirms that teaching the learner how to think is an important aim that carries with it very important future implications because this type of thinking requires learning skills in searching for information sources, selecting what is appropriate from it, and employing it in achieving its aims and addressing the problems that stand in its way. Despite the agreement of the majority of educators and decision-makers on the importance of developing thinking among learners, they still live with the practices that prevail in schools, most of which are not related to the development of thinking.

The science curricula that are taught by modern methods are considered a fertile and effective field for the development of scientific thinking among female students, in which the role of student is positive, and is not limited to being a recipient of information or an observer of the scene being planned. The teacher's employment of modern teaching methods and techniques that develop the students' thinking mindset, and also help them keep pace with the scientific revolution and employ scientific thinking skills.

\subsection{The Scientific Thinking Concept}

Scientific thinking has special importance in the field of science education; as the science curriculum includes a large number of operations needed by scientific activity: such as planning, hypothesis development, prediction, design, investigation, interpretation of results, communication, and a number of activities such as observation, definition, measurement, questioning, description, data collection, recording, and analyze it. These skills receive special attention, through training students, imparting it to them; they can employ it in many and varied fields that help them in their daily lives [1].

\subsection{The Importance of Scientific Thinking Skills}

Learning the scientific thinking skills is, in fact, a weapon 
for the individual to gain the ability to deal effectively with any kind of knowledge, information or variables that the future surprises them. Providing the scientific thinking skills makes one able to compete effectively in competition areas in this era, which success and excellence related to ability to think scientifically and master its skills [14].

Salih [16] also emphasizes that developing scientific thinking skills plays an essential role in providing students with research methods, thinking, experimentation and investigation, which enable them to understand and perceive scientific facts, and provide them with the possibility of proving their truth or falsehood.

Many educators unanimously agree that teaching and learning scientific thinking skills has become an important aim of education, and a major aim of teaching science. Kuhn [12] considered that teaching students the scientific method of thinking, and providing them with appropriate skills, is one of the most important aims of science education. Some foreign countries have also resorted to making scientific thinking a main aim of teaching science. The teaching science aims in Japan for the middle stage included developing and improving students' abilities and attitudes towards research in nature, through observation and experimentation [13].

\subsection{The Teacher Role in Developing Scientific Thinking Skills}

Many educators agree on the importance of the science teacher's role in developing students' scientific thinking skills, which are manifested in the following areas: mental knowledge, scientific knowledge, scientific thinking, sentimental, scientific and psychomotor tendencies, and among these skills What Ibn Hamid [11] put forward as follows:

1) Helping students to acquire scientific knowledge

2) Helping students to acquire appropriate scientific skills

3) Helping learners to develop the scientific method of thinking

4) Helping students to acquire appropriate attitudes in a functional manner

5) Helping students to acquire appropriate interests or tendency.

While Bin Salman [6] believes that the science teacher has a great role in helping female students acquire scientific thinking skills, as her role is manifested in the following:

1) Focusing on the practical aspect of science teaching and providing the opportunity for female students to carry out practical experiments in an investigative manner.

2) Stimulating female students' motivation through educational situations.

3) Using class questions at the appropriate time.

4) Employing scientific programs and activities appropriate to the level and abilities of female students.

5) Helping female students to analyze the scientific problems, they counter into sub-problems in order to facilitate it.

6) Training female students to write scientific reports on scientific events and to express their ideas and opinions freely.

7) Creating a conducive environment for a discussion and a logical scientific dialogue between the female students themselves, and between the female students and the teacher.

Ibn Hamid [11] also indicated that the teacher is one of the most important factors for the success of teaching scientific thinking skills, because the results achieved from the application of any program to teach scientific thinking depend to a large extent on the quality of education practiced by the teacher in the classroom. A list of characteristics and behaviors must be possessed by the teachers in order to provide the necessary classroom environment for the success of teaching process and learning scientific thinking skills, which are:

1) Listening to the students, so that the teacher can get to know the students' ideas closely.

2) Encouraging female students to debate scientifically and express their opinions.

3) Encouraging students to practice active learning.

4) Accept the students' ideas and respect their opinions.

5) Giving the students enough time to think about the educational activities, in order to highlight the value of thinking and reflection in solving problems.

6) Developing the students' self-confidence, as the teacher is required to provide opportunities for her students to accumulate successful experiences, so that their selfconfidence grows and their thinking skills improve.

7) Giving positive feedback to the students, and the necessity of encouraging and supporting of the teacher for students so as not to shake their self-confidence.

8) Valuing the students ideas. The teacher should not hesitate to point out the value of presented ideas of the students.

\section{Methodology and Procedures of the Research}

This research aimed to detect the practicing level of the scientific thinking skills in science by third intermediate grade students, by defining a specific methodology, and using tools to verify its validity and reliability.

\subsection{Methodology of the Research}

The descriptive analytical method was adopted in order to achieve the objectives of the research and answer its questions. The practice level of the third intermediate grade students of scientific thinking skills in science was revealed in three themes: the skill of doubt in information before acceptance, the skill of logical reasoning of information, and the skill of reliance on empirical evidence to judge Information. Then reaching conclusions that contribute to understanding the reality we study and contribute to its development. The descriptive approach is not limited to collecting information and data about the phenomenon, but 
rather it is necessary to classify this information quantitatively or qualitatively to reach results that help in understanding reality [5].

\subsection{Community and Sample of the Research}

The community of research consisted of all students and teachers of science in the third intermediate grade in the schools affiliated to Al-Nahda Education Office in eastern Riyadh, and their number was (5646) female students, and their teachers were (113) female teachers. Al-Nahda Education Office was chosen to represent the research community according to the population density in the region and the possibility of applying the research tools to the largest possible number of students.

In order to answer the research questions, a simple random sample was chosen at the rate of $10 \%$ of the female students' community and $30 \%$ of the female teachers' community for the academic year 1436/1437 AH. The number of female students was (673) whom the scientific thinking skills scale was applied, and the sample number of female teachers was (80) whom questionnaire was applied.

\subsection{Tools of the Research}

To answer the research questions, the researcher used two tools:

\subsubsection{The Scientific Thinking Skills Scale}

The researcher designed a scale to measure the practice level of scientific thinking skills among third intermediate grade students in science. It consists of (31) phrases distributed in three themes that were referred in Schafersman [17] study, as in Table 1:

Table 1. Distribution of the phrases of the Scientific Thinking Skills Scale on its three themes.

\begin{tabular}{lll}
\hline Themes of the scale & Phrase numbers & Total \\
\hline Doubt in information before acceptance & $1-10$ & 10 \\
Logical reasoning & $11-23$ & 13 \\
Reliance on empirical evidence & $24-31$ & 8 \\
Total & & 31 \\
\hline
\end{tabular}

The skill of doubt in information before acceptance: The researcher designed the phrases of this themes based on Hurtt's doubt scale, which was referred by Hussin [10] study. This scale is designed to measure the level of students' practice of the skill of doubt in information before acceptance, and the ability to distinguish between false and correct information with arguments and proofs. It consists of 10 phrases, and the student must choose one of the alternatives (agree/disagree) in proportion to the phrase. This theme is unique in its alternatives number from the rest of the scale themes in order to fit with the nature of the theme. The student is given one point for each correct answer and zero for each wrong answer. Thus, the total score for this section of the scale is 10 degrees.

The skill of logical reasoning of information: The researcher, based it on the scientific logic test prepared by Lawson [23] designed a logical reasoning scale commensurate with the Islamic faith and the age stage, in order to measure the level of students' practice of the skill of arriving at an initial conception of a particular phenomenon by searching for related reasons and provide a logical explanation for it. It consists of (13) phrases, each of which has one correct answer. The student is given one point for each correct answer and zero for each wrong answer. Thus, the total score for this section of the scale is 13 degrees.

The skill of reliance on empirical evidence to judge information: The researcher relied on the science book for the third intermediate grade in designing its phrases. This scale is designed to measure the level of the student's practise of the skill of reaching her conclusions and judgments based on practical experiences and activities. It consists of (8) phrases, each with one correct answer, and the student must choose from the four alternatives the method she prefers to verify the phrase. The student is given one point for each correct answer and zero for each wrong answer. Thus, the total score of the scale section is (8) degrees.

\subsubsection{The Second Tool: The Questionnaire}

The researcher designed a questionnaire directed to science teachers according to the binary Likert scale, and using the scale: (agree, disagree) to judge the level of practicing the scientific thinking skills by third-intermediate grade students and comparing its results with the scale results, so that its phrases fit with the included themes in the scale tool. The questionnaire included (32) phrases representing the students' performance of scientific thinking skills distributed in three themes, as in the table 2:

Table 2. Distribution of the questionnaire's phrases on its three themes.

\begin{tabular}{lll}
\hline Themes of the questionnaire & Phrase numbers & Total \\
\hline Doubt in information before acceptance & $1-10$ & 10 \\
Logical reasoning & $11-18$ & 8 \\
Reliance on empirical evidence & $19-32$ & 14 \\
Total & & 32 \\
\hline
\end{tabular}

\subsection{Procedures of the Research}

After completing the preparation of the research tools and ensuring its validity and reliability, the researcher followed the following steps to apply the research tools:

1) The first research tool, the scale, was applied on the research sample, which numbered (673) female students, and the tool was distributed to them during the researcher's visit to the schools of the research sample.

2) The second research tool, the questionnaire, was applied on a sample of the research consisting of (80) female teachers to measure the level of the third intermediate grade students' practice of scientific thinking skills in science.

3) The researcher used the statistical software package for the social sciences (SPSS) to process the data statistically and answer the research questions.

4) Writing results, analyzing, interpreting, linking it to results of the relevant studies, and then writing the research in its final form, including the most important recommendations and suggestions. 


\section{Results}

To answer the main question: What is the practice level of the scientific thinking skills in science by third intermediate grade students? Frequencies, percentages, arithmetic mean, and standard deviation were used in the themes of the scientific thinking skills scale and the questionnaire in general. This is represented in Table 3 for the scale and Table 4 for the questionnaire (Female teachers' opinion):

Table 3. Frequencies, percentages, arithmetic mean and standard deviation of the themes of the scientific thinking skills scale in general ( $N=673)$.

\begin{tabular}{|c|c|c|c|c|c|c|c|}
\hline $\mathbf{S}$ & Themes & $\begin{array}{l}\text { Frequencies and percentages } \\
\text { of correct answers }\end{array}$ & $\begin{array}{l}\text { Frequencies and percentages of } \\
\text { wrong answers }\end{array}$ & Mean & $\begin{array}{l}\text { Standard } \\
\text { deviation }\end{array}$ & $\begin{array}{l}\text { Phrases } \\
\text { Number }\end{array}$ & Sort \\
\hline & $\begin{array}{l}\text { The skill of doubt in information } \\
\text { before acceptance }\end{array}$ & $\begin{array}{l}4797^{*} \\
71 \%\end{array}$ & $\begin{array}{l}1933^{* * *} \\
29 \%\end{array}$ & 7.1 & 0.16 & 10 & 1 \\
\hline & The skill of logical reasoning & $\begin{array}{l}2542 \\
29 \%\end{array}$ & $\begin{array}{l}6207 \\
71 \%\end{array}$ & 3.8 & 0.13 & 13 & 3 \\
\hline & $\begin{array}{l}\text { The skill of reliance on empirical } \\
\text { evidence to judge Information }\end{array}$ & $\begin{array}{l}1746 \\
32 \%\end{array}$ & $\begin{array}{l}2638 \\
68 \%\end{array}$ & 2.6 & 0.22 & 8 & 2 \\
\hline
\end{tabular}

(*) The total number of students correct responses to the phrases of the entire theme.

(**) The total number of students wrong responses to the phrases of the entire theme.

It can be seen from Table 3 that the general arithmetic mean of the students' practice of all skills of the scale in its entirety reached (13.5) out of (31) which is the number of the scale phrases. In addition, a standard deviation of $(0.10)$, that is: a practice percentage equal to $(43.5 \%)$, and this percentage falls in the range $(25 \%-<50 \%)$, which is the criterion that was adopted to judge the level of female students' practice of scientific thinking skills. This indicates that the practice level of scientific thinking skills by third intermediate grade students in science is low.

Table 4. Frequencies, percentages, mean and standard deviation for each of the themes and for the questionnaire in general $(N=80)$.

\begin{tabular}{|c|c|c|c|c|c|c|c|}
\hline $\mathbf{S}$ & Themes & $\begin{array}{l}\text { Frequencies and } \\
\text { percentages of teachers } \\
\text { responses with agreement }\end{array}$ & $\begin{array}{l}\text { Frequencies and percentages of } \\
\text { teachers responses with } \\
\text { disagreement }\end{array}$ & Mean & $\begin{array}{l}\text { Standard } \\
\text { deviation }\end{array}$ & $\begin{array}{l}\text { Phrases } \\
\text { Number }\end{array}$ & Sort \\
\hline & $\begin{array}{l}\text { The skill of doubt in information } \\
\text { before acceptance }\end{array}$ & $\begin{array}{l}502 * \\
6371 \%\end{array}$ & $\begin{array}{l}298 * * \\
37 \%\end{array}$ & 6.3 & 0.20 & 10 & 3 \\
\hline & The skill of logical reasoning & $\begin{array}{l}541 \\
85 \%\end{array}$ & $\begin{array}{l}99 \\
15 \%\end{array}$ & 6.8 & 0.14 & 8 & 1 \\
\hline & $\begin{array}{l}\text { The skill of reliance on empirical } \\
\text { evidence to judge Information }\end{array}$ & $\begin{array}{l}742 \\
66 \%\end{array}$ & $\begin{array}{l}378 \\
34 \%\end{array}$ & 9.2 & 0.11 & 14 & 2 \\
\hline \multicolumn{2}{|r|}{$\begin{array}{l}\text { The general arithmetic average of all } \\
\text { skills }\end{array}$} & $\begin{array}{l}1785 \\
69.7 \%\end{array}$ & $\begin{array}{l}775 \\
30.3 \%\end{array}$ & 22.3 & 0.09 & 32 & - \\
\hline
\end{tabular}

(*) Total number of teachers' agreement responses for entire theme phrases.

(**) Total number of teachers' disagreement responses for entire theme phrases.

While it is noted from Table 4, which represents the teachers opinion, that the general arithmetic average of the teachers responses in agreement with all themes of the questionnaire reached $(22,3)$ out of $(32)$, which is the number of the questionnaire phrases, with a standard deviation of (0.09). That is an agreement percentage equals $(69.7 \%)$, and this percentage falls in the range $(50 \%-<75 \%)$, which is the criterion that was adopted to judge. This indicates that the level of female students' practice of scientific thinking skills in Science subject is considered high from the point of view of their teachers.

Tables 3 and 4 also show the level of students' practice of scientific thinking skills for each of the scale and questionnaire themes, respectively. Looking at Tables 3 and 4, it can be noted that:

1) The first theme, which represents the skill of doubt in information before acceptance, came in the scale as in Table 3 in the first place with an arithmetic mean of (7.1) out of (10), which is the number of phrases of the theme, with a standard deviation of $(0.16)$. That is equivalent to $(71 \%)$ of the general practice of female students on phrases of the first theme, and this percentage falls in the range $(50 \%-<75 \%)$. This indicates that the level of female students' practice of the skill of doubt in information before acceptance is considered high. While it ranked third in the questionnaire as in Table 4, with an arithmetic average of (6.3) out of (10), which is the number of phrases for the first theme, with a standard deviation of $(0.20)$. That is equivalent to $(63 \%)$ of the response the general college of female teachers depends on the expressions of the first axis, and this percentage falls in the range $(50 \%-<75 \%)$. This indicates that the level of female students' practice of the skill of doubt in information before acceptance from the teachers' point of view is considered high. This is consistent with the scale results.

2) The second theme, which represents the skill of logical reasoning of information, came in the scale in the third place as in Table 3 with an arithmetic mean of (3.8) out of (13) which is the number of phrases of the theme, 
with a standard deviation of (0.13). That is equivalent to $(29 \%)$ of the general practice of the female students on phrases of the second toipc, and this percentage falls in the range $(25 \%-<50 \%)$. This indicates that the level of students' practice of the skill of logical reasoning of information is considered low. While the skill of logical reasoning ranked first in the questionnaire as in Table 4, with an arithmetic average of (6.8) out of (8), which is the number of phrases for the second theme, with a standard deviation of (0.14). It is equivalent to $(85 \%)$ from the overall response of the female teachers to the second theme phrases, and this percentage falls in the range $(75 \%-<100 \%)$. This indicates that the level of students' practice of the skill of logical reasoning of information from the teachers' point of view is very high, and this differs greatly from the scale results.

3) The third theme, which represents the skill of reliance on empirical evidence to judge information, came in the scale in the second place as in Table 3 , with a mean of (2.6) out of (8), which is the number of phrases of the theme, with a standard deviation of $(0.22)$. That is, it is equivalent to $(32 \%)$ of the general practice of female students on the third theme, and this percentage falls in the range $(25 \%-<50 \%)$. This indicates that the level of female students' practice of the skill of reliance on empirical evidence to judge information is low. This skill ranked second in the questionnaire as in Table 4, with an arithmetic mean of (9.2) out of (14), which is the number of theme phrases, with a standard deviation of $(0.11)$. This is equivalent to $(66 \%)$ of the total general response of female teachers depend on the expressions of the third theme, this percentage lies in the range $(50 \%-<75 \%)$. This indicates that the level of female students' practice of the skill of reliance on empirical evidence to judge information from the female teachers' point of view is considered high. This varies with scale results.

\section{Discussion}

By comparing results of the scale with results of the questionnaire, it was found that its results agreed that the level of students' practice of doubt skill (first theme) was high. While its results varied with respect to the practice level of logical reasoning (second theme), and the use of empirical evidence (third theme) skills, which were low in the scale and high in the questionnaire, this can be explained by the following:

1) That the skill of doubt in information before acceptance, can be observed through the students behavior; therefore, the science teachers responses in the questionnaire were in agreement with the female students responses in the scale related to the first theme (the skill of doubt in information before acceptance).

2) The skill of logical reasoning for information can be observed through the students' practice of it. However, the responses of the science teachers in the questionnaire were very different from the responses of the female students in the scale related to the second theme (the skill of logical reasoning of information). This may be due to the subjectivity of the teachers in judging the questionnaire phrases and the impact of this on their assessment of the level of their actual students' practice of the skill of logical reasoning for information.

3) The skill of reliance on empirical evidence to judge information can also be observed through the behavior of the students. Therefore, the teachers' opinion about the level of their students' practice of this skill was close to the actual level of the students' practice on the scale. The difference between the two results in the third theme (the skill of reliance on empirical evidence to judge information) may be due to the teachers overestimating the level of their students' actual practice in the classroom environment of skills scientific thinking.

Reality remains the best proof of the level of students' practice of their scientific thinking skills, by applying the scale on a random sample of third-grade intermediate students; results of the scale are more accurate than the obtained results from the questionnaire in determining the level of practice of scientific thinking skills by third-grade intermediate students in science. In addition, the obtained result from the scale, are closer to reality, and the closest to results of the related studies; which makes it more valid and accurate than the results of the questionnaire and this result is consistent with the results of the previous studies such as AlZughaibi [22] study, which showed the poor level of students' practice of scientific thinking skills.

The low level of female students' practice of scientific thinking skills in science, which was shown by the results of the scale, despite the development of science curricula, may be attributed to the following reasons:

1) Lack of educational and training programs for female students, which contribute to the development of their scientific thinking skills.

2) Some teachers' lack of integration and linking between knowledge in science subject, and between science and rest of the study subjects, and the importance of this in providing an integrated knowledge and experiences linked to reality.

3) Some teachers misuse learning theories and modern teaching methods, which are effective in developing students' scientific thinking skills.

4) The depth of gap between understanding and practice of the scientific thinking skills among some female teachers.

5) The level of self-efficacy of female teachers, and their educational level, both of which have an impact on the development of scientific thinking skills among their students.

\section{Conclusion}

The researcher thanks Allah, the Most High, the Great, 
first and foremost, for his good success, generous help, and for the achievement of this research, and blessings and peace be upon the teacher of humanity and the guide of humanity, his family companions, and those who followed them in goodness until the Day of Judgment...

The researcher extend deep thanks and gratitude to the Ministry of Education, which gave the opportunity to complete postgraduate studies, and made it easier to collect information and statistics and conduct field tests.

The researcher also extend thanks and gratitude to distinguished professors, Ali ibn Ahmed Al-Rashed and Mohammed ibn Rashid Al Sharqi, who did not hesitate and spare no effort in guiding and guiding the researcher from the beginning of the research until the final touches were put in it, so may God reward them.

The researcher also pointed out that the development of scientific thinking skills in young people is an inevitable necessity dictated by the renewable conditions of life and its rapid pace for the problems faced by young people in their daily lives, so identifying these skills is a necessary duty to use them optimally.

The researcher believes that acquiring scientific thinking skills requires students to practice it through classroom and extracurricular activities, and to receive educational courses and programs, which effectively contribute to the development of their scientific thinking skills. This in turn requires teachers to employ modern theories and strategies when planning the curriculum, and this requires them time and effort.; This led to the reluctance of many female teachers to employ it ineffectively, and consequently the low level of students' practice of scientific thinking skills. It is unfair to judge the performance of female teachers as inferior. This may be due to the ineffectiveness of some of training courses, which is a theory that lacks an applied aspect, which in turn affects the low level of female performance.

\section{Recommendations of the Research}

Based on results of the current research, the research recommends the following:

1) Constructing enrichment programs and materials which aim to the development of the students' scientific thinking skills, and giving them the opportunity to interact directly with these programs.

2) Activating the role of scientific clubs in schools, encouraging female students to join it, and conducting non-classroom activities that contribute to the development of their scientific thinking skills.

3) Providing practical models in science curricula lessons that provide strategies that develop scientific thinking skills; So that science teachers can benefit from it in their teaching.

4) Providing training programs for science teachers during their service in teaching methods that develop scientific thinking skills and following up on the results of these programs in the classroom.

\section{References}

[1] Abu Hamdan, Jamal bin Abdul Jalil. (2006). The level of scientific thinking among students of the higher stage of basic education and its relation to some personal and scholastic factors. (Unpublished $\mathrm{PhD}$ thesis), Department of Curriculum and Instruction, Faculty of Postgraduate Studies, University of Jordan.

[2] Aldahmash, Abdul-Wali ibn Husayn., Nu'man, Abd al-Qawi bin Muhammad, \& Al-Farrad, Zekra Bint Ali. (2014). The effect of using the Bibi structural model in modifying alternative perceptions of Science subject among the female students of basic eighth grade. The Arab Journal of Science and Technology Education, (University of Science and Technology in Yemen), 16 (2), 54-79.

[3] Al-Hadabi, Daoud Abdul-Malik \& Al-Jajji, Raja Muhammed Deeb. (2009). The effectiveness of the integrative approach in developing scientific thinking skills for female students of the second year of scientific secondary school. The Sixth Arab Scientific Conference for the Gifted and Talented - Caring for the gifted is an imperative for a better Arab future: The Arab Council for the Gifted and Talented, Part 1, Amman, 101-126.

[4] Almasaeed, Aslan bin Subh. (2011). Scientific thinking among university students and its relation to general selfefficacy based on some variables. Journal of the Islamic University (Human Studies Series), (Gaza), 19 (1), 679-707.

[5] Al-Zahar, Najah bin Ahmad. (2005). Brief Guide in Writing Scientific Research. Dar Almohammadi for Publishing and Distribution.

[6] Bin Salman, Amal Bint Mohammad. (2011). The effectiveness of using the Tareez Theory in the development of scientific thinking and academic achievement in the developed science course among fourth-grade primary female students in Makkah. (Unpublished Master's thesis), Department of Curriculum and Instruction, Faculty of Education, Umm Al-Qura University.

[7] Deeb, Hamza bin Yusuf. (2009). Strategic thinking and its role in developing the leaderships of Palestinian Preventive Security. (Unpublished Master's Thesis), Department of Administrative Sciences, Faculty of Postgraduate Studies, Naif Arab University for Security Sciences.

[8] EL-Sabagh, H. A. (2010). The Impact of a Web-Based Virtual $\mathrm{Lab}$ on the Development of Students' Conceptual Understanding and Science Process Skills. PhD dissertation Unpublished, Educational Technology Department, Faculty of Education, Dresden University of Technology, Germany.

[9] Fouad, Manal bint Abu Al-Hassan. (2003). Ways to raise the efficiency of media professionals dealing with children to develop scientific thinking and fight myths. A scientific seminar on the theme of 'The development of scientific thinking and the elimination of superstitious thinking among children', Child Care Center, Mansoura University, Egypt.

[10] Hussin, S. A. \& Iskandar, T. M. (2013). Exploratory Factor Analysis on Hurtt's Professional Skepticism Scale: A Malaysian Perspective. Asian Journal of Accounting and Governance. (4), 11-19.

[11] Ibn Hamid. Lakhdar. (2011). The effect of using a computer program on developing scientific thinking skills in the light unit of Physics course among medium third-year students. MÂAREF Journal, Bouira University, (4), 190-212. 
[12] Kuhn, D. (2010). What Is Scientific Thinking And How Does It Develop? In U. goswami (Ed), Blackwell Handbook of Childhood Cognitive Development (371-393). Oxford, England: Blackwell.

[13] Minstrell, J. \& Van Zee, E. H. (Eds.) (2000). Lnquiring into Inquiry Learning and Teaching in Science. Washington, D.C.: American Association for the Advancement of Science.

[14] Paul, R. \& Elder, L. (2003). A miniature guide for students and faculty to the foundations of analytic thinking: how to take thinking apart and what to look for when you do. Dillon Beach, CA: Foundation for Critical Thinking.

[15] Remigio, K. B., Yangco, R. T., \& Espinosa, A. A. (2014). Analogy-Enhanced Instruction: effects on reasoning skills in science. The malaysian online Journal of educational science. $2(2), 1-9$.

[16] Salih, M. (2010). Developing Thinking Skills in Malaysian Science Students via an Analogical Task. Journal of Science and Mathematics. 33 (1), 110-128.

[17] Schafersman, S. D. (1997). An Introduction to Science: Scientific Thinking and the Scientific Method. Schafersman Department of Geology. Miami Universit, Retrieved $17 / 10 / 2015$ from: http://www.geo.sunysb.edu/esp/files/scientific-method.html.

[18] Silk, E. M., Schunn, C. D., \& Cary, M. S. (2009). The Impact of an Engineering Design Curriculum on Science Reasoning In an Urban Setting. Journal of Science Education and Technology. 18 (3), 209-223.

[19] Yasin, Thanaa Muhammad. (2013). The effectiveness of the problem-solving method in applied sciences on academic achievement and the development of creative thinking skills among second-grade students. Umm Al-Qura University Journal of Educational and Psychological Sciences, (Makkah), $5(1), 86-87$.

[20] Zimmerman, C. (2007). The Development of Scientific Thinking Skills In Elementary and Middle School. Developmental Review. 27 (2), 172-223.

[21] Ministry of Education. (1995). Education policy document in the Kingdom of Saudi Arabia. ( $4^{\text {th }}$ ed), Riyadh: Al Bayan Press.

[22] Al-Zughaibi, Ghassan ibn Mohammed. (2004). The level of scientific thinking skills used by third-grade intermediate students in the Kingdom of Saudi Arabia. Unpublished Master's Thesis, Department of Curricula and Teaching Methods, College of Graduate Studies, University of Jordan, Amman, Hashemite Kingdom of Jordan.

[23] Lawson, A. E. (1978). Development and Validation of the Classroom Test of Formal Reasoning. Journal of Research in Science Teaching. 15 (1), 11-24. 